\title{
ESTIMATION OF RIGHT VENTRICULAR OUTPUT IN MAN USING RADIOACTIVE KRYPTON $\left(\mathrm{KR}^{85}\right) *$
}

\author{
By D. F. ROCHESTER,† J. DURAND, $\ddagger$ J. O. PARKER,§ H. W. FRITTS, JR. AND \\ R. M. HARVEY \\ (From the Department of Medicine, Columbia University, College of Physicians and Surgeons, \\ and the Cardio-Pulmonary Laboratory of the First Medical and Chest Services, \\ Columbia University Division, Bellevue Hospital, New York, N. Y.)
}

(Submitted for publication August 10, 1960; accepted December 12, 1960)

Of the several methods known to provide reliable estimates of the cardiac output, none will satisfactorily follow the variations in flow which occur during transient states in man. For instance, the conventional Fick method is applicable only under steady conditions $(1,2)$. Further, dilution methods, employing intravenous injections of indicators, may estimate the cardiac output when flow is changing, but the number of estimates obtainable in any transient period is limited by the time required to inscribe each primary dilution curve. This limitation was circumvented by Shepherd, Bowers and Wood (3), who infused Evans blue dye at a constant rate. Since they continued the infusion for only 30 seconds, the accumulation of dye in the blood stream did not present a problem; however, prolongation of such an infusion is impractical because of the possibility of discoloring the patient's skin. Similarly, the substitution of an isotope for dye may present a radiation hazard.

A preliminary report from this laboratory has shown that by using the gaseous radioisotope, krypton $^{85}$, in continuous infusion, the limitation of time may no longer apply (4). The purpose of this paper is to report further experience with this method, to describe in detail its principle, to compare the flows obtained by the conventional Fick and by the $\mathrm{Kr}^{85}$ methods under steady conditions, and to present the estimates of flow made with $\mathrm{Kr}^{85}$ during changing states.

* This investigation was supported by a research grant (Public Health Service Grant H-2001 C) from the National Heart Institute, Bethesda, Md.

† Fellow of the Life Insurance Medical Research Fund. Present address: Captain MC USAR, 34th General Hospital, La Chapelle St., Mesmin, France.

$\ddagger$ Research Fellow (HTS 5320) of the National Heart Institute.

$\S$ Fellow of the New York Heart Association.
THEORETICAL CONSIDERATIONS

Principle. $\mathrm{Kr}^{85}$ is a chemically inert, poorly soluble gas emitting 99 per cent $\beta$-particles. When dissolved in sterile saline and infused into either a great vein or into the right atrium, it first mixes with the blood in the right ventricle, then enters the pulmonary vessels where most of the isotope escapes into the alveoli and leaves the body in the expired air. Thus, as depicted in Figure 1, only a small amount reaches the left atrium and ventricle, and, until the tissues are saturated, an even smaller amount returns to the chambers of the right heart.

If one could sample blood simultaneously from the pulmonary artery and a hypothetical point in the great veins where all of the blood returning from the tissues is thoroughly mixed, then the following application of the Fick principle would provide a value of right ventricular flow $(\dot{Q})$.

$$
\dot{\mathrm{Q}}=\frac{\dot{\mathrm{q}}_{\mathrm{I}} \mathrm{C}_{\mathrm{I}}}{\mathrm{C}_{\mathbf{P A}}-\mathrm{C}_{\overline{\mathbf{v}}}}
$$

where $\mathrm{C}_{\mathrm{PA}}=$ concentration of $\mathrm{Kr}^{85}$ in the pulmonary arterial blood, $C_{\bar{v}}=$ concentration of $\mathrm{Kr}^{85}$ in the hypothetical mixed venous sample, $\mathrm{C}_{\mathrm{I}}=$ concentration of $\mathrm{Kr}^{85}$ in the infusate, and $\dot{\mathrm{q}}_{\mathrm{I}}=$ rate of infusion.

Since, however, the hypothetical point for obtaining a venous sample does not exist when a constant infusion is given anywhere in the venous side of the circulation, $\mathrm{C}_{\overline{\mathrm{v}}}$ cannot be measured and must be estimated from the concentration of $\mathrm{Kr}^{85}$ in a sample collected from the brachial artery $\left(C_{a}\right)$. Under these circumstances, $C_{a}$ replaces $C_{\bar{v}}$ in the equation; the validity of this replacement will be discussed subsequently.

Analysis of errors. In applying this principle, it is first assumed that there is no loss of krypton between the point of infusion and the pulmonary 


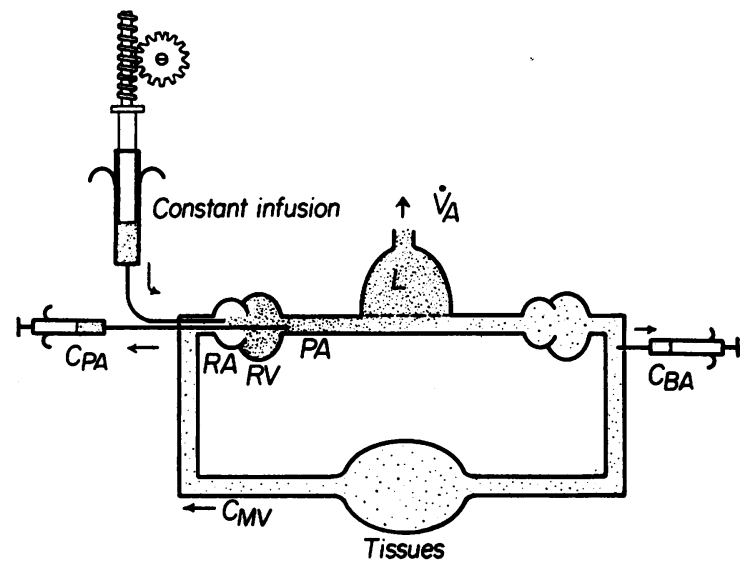

Fig. 1. A schematic Representation of the circuLATION TO SHOW SITES OF INJECTION AND SAMPLING OF KRYPTON. $V_{\mathbf{A}}=$ alveolar ventilation, $\mathrm{C}_{\mathbf{P}_{\mathbf{A}}}=$ concentration of $\mathrm{Kr}^{85}$ in the pulmonary artery, $\mathrm{C}_{\mathrm{BA}}=$ concentration of $\mathrm{Kr}^{85}$ in the brachial artery, $\mathrm{C}_{\mathrm{mv}}=$ concentration of $\mathrm{Kr}^{85}$ in mixed venous blood (called $\mathrm{C}_{\overline{\mathrm{v}}}$ in text). $\mathrm{L}=$ lungs, $\mathrm{RA}=$ right atrium, $\mathrm{RV}=$ right ventricle, $\mathrm{PA}=$ pulmonary artery.

artery. This cannot be validated under the conditions of a constant infusion experiment, but Fritts and associates (5) have shown this to be true during single injections.

Secondly, one must assess the extent to which the right ventricle, while acting as a mixing chamber, retards the appearance of a new fixed level of $\mathrm{Kr}^{85}$ concentration in pulmonary arterial blood following a change in flow, such as that which may occur during exercise. Thus, if there is a sudden change in flow from a constant value $(\dot{Q})$ to a new constant value $\left(\dot{Q}_{1}\right)$, the change in the pulmonary arterial concentration of $\mathrm{Kr}^{85}$ is given by Equation 2:

$$
\begin{aligned}
\mathrm{C}_{\mathrm{PA}}(\mathrm{t}) & =\frac{\dot{\mathrm{q}}_{\mathrm{I}} \mathrm{C}_{\mathrm{I}}+\dot{\mathrm{Q}}_{1} \mathrm{C}_{\overline{\mathrm{v}}}}{\dot{\mathrm{Q}}_{1}} \\
& -\left(\frac{\dot{\mathrm{q}}_{\mathrm{I}} \mathrm{C}_{\mathrm{I}}+\dot{\mathrm{Q}}_{1} \mathrm{C}_{\overline{\mathrm{v}}}}{\dot{\mathrm{Q}}_{1}}-\mathrm{C}_{\mathrm{PA}}\right) \mathrm{e}^{-\left(\dot{\mathrm{Q}}_{1} / \mathrm{v}\right) \mathrm{t}}
\end{aligned}
$$

where $\mathrm{C}_{P_{A}}(t)=$ concentration of $\mathrm{Kr}^{85}$ in the pulmonary arterial blood after the change in flow, $t=$ time elapsed after the change in flow, and $\mathrm{V}=$ volume of the right ventricle. When the new equilibrium concentration $\left(\mathrm{CPA}_{1}\right)$ is reached, Equation 2 reduces to

$$
\mathrm{C}_{\mathrm{PA}_{1}}=\frac{\dot{\mathrm{q}}_{\mathrm{I}} \mathrm{C}_{\mathrm{I}}+\dot{\mathrm{Q}}_{1} \mathrm{C}_{\overline{\mathrm{v}}}}{\dot{\mathrm{Q}}_{1}}
$$

which is merely Equation 1 in rearranged form.
It can be seen from Equation 2 that blood flow as estimated from $C_{P_{A}}$ will initially not reflect the magnitude of a sudden change in flow. However, even under the most adverse conditions, when the volume of the right ventricle is large and flow through it is small, as may occur in congestive heart failure, the time required for $\mathrm{C}_{P A}(t)$ to approximate the new equilibrium level is short. For example, if the right ventricular volume were $400 \mathrm{ml}$ and the new average flow through it were $40 \mathrm{ml}$ per second, then in 20 seconds $C_{P A}(t)$ would reflect 85 per cent of the change from $\dot{Q}$ to $\dot{Q}_{1}$. The sampling time of 5 seconds does, of course, mask cyclic variations in output whose periodicity is less than $\mathbf{5}$ seconds.

The third and major problem which arises in using this technique concerns the validity of substituting the concentration of krypton in the brachial artery for that of the mixed venous blood which cannot be obtained. This substitution requires justification: for purposes of simplification, one may treat normal lungs as if 1) their ventilation-perfusion ratios are homogeneous, 2) the concentration of $\mathrm{Kr}^{85}$ in the endcapillary blood is in equilibrium with that in the alveolar gas, and 3) all of the blood contacts alveoli. Under such circumstances, the brachial arterial blood will have the same krypton concentration as blood leaving the alveolar capillaries, and, with steady flow and ventilation, the concentration of $\mathrm{C}_{\mathrm{a}}$ is given by Equation 3 :

$$
\mathrm{C}_{\mathrm{a}}=\mathrm{C}_{\mathrm{a}}^{\prime}=\mathrm{C}_{\mathrm{PA}}\left(\frac{\lambda \dot{\mathrm{Q}}}{\dot{\mathrm{V}}_{\mathrm{A}}+\lambda \dot{\mathrm{Q}}}\right)
$$

where $\mathrm{C}^{\prime}{ }_{\mathrm{c}}=$ concentration of $\mathrm{Kr}^{85}$ in end-capillary blood, $\dot{Q}=$ pulmonary blood flow, $\mathrm{V}_{\mathrm{A}}=$ alveolar ventilation, and $\lambda=0.06$, the solubility coefficient of $\mathrm{Kr}^{85}$ in blood at $37^{\circ} \mathrm{C}$. With normal values for cardiac output and alveolar ventilation substituted into Equation 3, the formula shows that $C_{a}$ should be from 7 to 10 per cent of $C_{P A}$. Indeed, in 15 patients without pulmonary emphysema, the average value was 8.8 per cent with a range of 6.8 to 11.5 per cent.

Since there is tissue uptake of krypton, the concentration of the isotope in the brachial arterial blood will exceed that in the mixed venous blood until equilibrium is reached. This difference was determined experimentally in five studies in which the infusion was made into the 


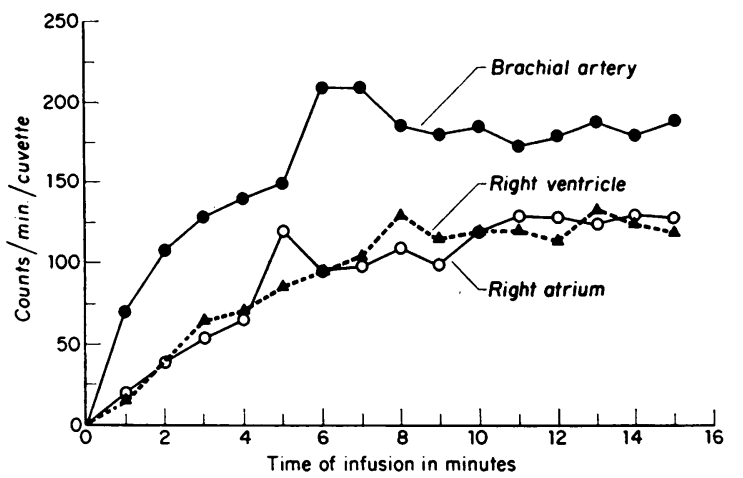

Fig. 2. Graphic Representation in one patient of THE TIME CONCENTRATIONS OF $\mathrm{KR}^{85}$ IN BRACHIAL ARTERIAL, RIGHT VENTRICCLAR AND RIGHT ATRIAL BLOOD SAMPLES DURING A CONSTANT INFUSION INTO THE PULMONARY ARTERY.

pulmonary artery rather than into the right atrium, thus permitting sampling from the right atrium or ventricle. Figure 2 illustrates the results of a typical study. It can be seen that the krypton concentrations in both the arterial and mixed venous bloods rose in a curvilinear fashion over a 4 to 5 minute period and then became nearly constant for as long as the infusion was continued.

When the krypton concentration in the brachial arterial bood has reached a plateau, the krypton concentration in the mixed venous blood is approximately 65 per cent of the brachial arterial concentration. Thus, because of the very large difference between $C_{P A}$ and $C_{B A}$, substituting $C_{a}$ for $C_{\bar{v}}$ leads to an overestimation of the cardiac output of normal subjects of less than 3 per cent.

If, after constant levels of krypton have been reached the blood flow and ventilation are suddenly increased, the relationship between $\mathrm{C}_{\mathrm{PA}}$, $\mathrm{C}_{\mathrm{a}}$ and $\mathrm{C}_{\overline{\mathrm{v}}}$ may change. For example, if at the onset of exercise there is a disproportionate increase in ventilation, as compared with that in blood flow, the concentration in the brachial artery will decrease faster than that in the mixed venous blood and $C_{a}$ will be smaller than $C_{\bar{v}}$. As a result, the cardiac output will be underestimated, but comparison of krypton concentrations again indicates that in normal subjects the maximum error will be no more than 3 per cent.

\section{METHODS}

The infusion was prepared by equilibrating a volume of gaseous krypton with sterile physiological saline at room temperature. The concentration of krypton was approximately $50 \mu \mathrm{c}$ per $\mathrm{ml}$ when the infusion rate of 5 $\mathrm{ml}$ per minute was used, or $250 \mu \mathrm{c}$ per $\mathrm{ml}$ for an infusion rate of $1 \mathrm{ml}$ per minute. For an infusion period of 20 minutes, the total dose of krypton would amount to $5 \mathrm{mc}$. Under these conditions, it can be calculated that the tissue receiving the greatest amount of radiation, the tracheal epithelium, would absorb not more than 4 rads, even if alveolar ventilation were low.

A Phipps and Bird syringe driver accurate to \pm 0.5 per cent coupled to a greased $100 \mathrm{ml}$ syringe containing the infusate was used in order to deliver the solution of the tracer through a no. 6 cardiac catheter.

The concentration of krypton in blood, and, after dilution, in the infusate, was measured by the method of Lassen and Munck (6) and expressed as counts per minute per cuvet. For this purpose, $4 \mathrm{ml}$ of blood was drawn anaerobically into a syringe. The dead space of the syringe was filled with Triton $\mathrm{X}-100$ in $0.1 \mathrm{M}$ sodium borate to hemolyze the blood. The hemolyzed specimen was then transferred to an airtight disc-shaped cuvet of $1.5 \mathrm{ml}$ volume, and the emitted radiation counted simultaneously from each face by a pair of GeigerMüller tubes. Rapid complete filling of the cuvets is essential in order to avoid escape of krypton from the liquid phase into the air phase. Such escape will result in an underestimation of the krypton concentration in the sample. On the other hand, if even very small air bubbles are trapped in the cuvet during filling, an overestimation of the krypton concentration in the sample will follow, since these bubbles will accumulate krypton from the sample and because there is a sixfold greater counting efficiency for krypton in the gaseous than in the fluid phase (7). Since krypton is less soluble at higher temperatures, warming of the cuvet after it has been filled and sealed will also lead to an overestimation of the $\mathrm{Kr}^{85}$ concentration because of the formation of small bubbles.

The Fick determination was performed using techniques previously described in this laboratory.

\section{PATIENT MATERIAL AND PROCEDURE}

The 15 patients studied represented a variety of diseases, including: pulmonary tuberculosis, 5; Laennec's cirrhosis 2, resolving pneumonia, 1 ; healed lung abscess, 1 ; hilar adenopathy, 1 ; cerebral arteriosclerosis, 1 ; calcified pericardium, 1; hypertensive heart disease, 1; hemorrhoids, 1 ; and undiagnosed heart disease, 1 . With the exception of the last patient, none of the subjects had ever been in congestive heart failure. This excepted patient had recently recovered from cardiac insufficiency.

Each patient was studied in a fasting state, without premedication. Separate catheters were placed in the pulmonary artery and in the right atrium in the usual fashion. The use of a double lumen catheter is not recommended because of the fact that, with the terminal openings $12 \mathrm{~cm}$ apart, unusually high krypton concentrations occasionally have been obtained from the pulmonary artery, presumably due to axial streaming of the 
TABLE I

Results of a typical study*

\begin{tabular}{|c|c|c|c|c|c|c|c|}
\hline Condition & $\begin{array}{c}\text { Minutes } \\
\text { after } \\
\text { start of } \\
\text { infusion }\end{array}$ & $\dot{q}_{\mathrm{I}}$ & $\mathrm{C}_{\mathrm{I}}$ & $\mathrm{C}_{P A}$ & $\mathrm{C}_{\mathrm{a}}$ & $\dot{Q}_{k r}$ & $\dot{\mathbf{Q}}_{\text {Fick }}$ \\
\hline Rest & $\begin{array}{l}4 \\
5 \\
6 \\
7 \\
9\end{array}$ & 5 & $3,635,900$ & $\begin{array}{l}2,665 \\
2,174 \\
2,597 \\
2,832 \\
2,749\end{array}$ & $\begin{array}{l}283 \\
265 \\
308 \\
309 \\
308\end{array}$ & $\begin{array}{l}7.94 \\
7.21 \\
7.45\end{array}$ & 7.83 \\
\hline Exercise & $\begin{array}{l}10 \\
11 \\
13 \\
14 \\
15 \\
17 \\
18 \\
19\end{array}$ & & & $\begin{array}{l}2,190 \\
2,190 \\
2,233 \\
2,066 \\
2,213 \\
1,972 \\
2,053 \\
2,004\end{array}$ & $\begin{array}{l}276 \\
206 \\
197 \\
155 \\
162 \\
149 \\
172 \\
164\end{array}$ & $\begin{array}{l}9.50 \\
9.16 \\
8.93 \\
9.51 \\
8.86 \\
9.97 \\
9.67 \\
9.88\end{array}$ & 9.51 \\
\hline
\end{tabular}

${ }^{*} \dot{\mathrm{q}}_{\mathrm{I}}=$ rate of infusion $(\mathrm{ml} / \mathrm{min}) ; \mathrm{C}_{\mathrm{I}}=$ concentration of $\mathrm{Kr}^{85}$ in the infusate (counts/cuvet $\left./ \mathrm{min}\right) ; \mathrm{C}_{\mathrm{PA}}=$ concentration of $\mathrm{Kr}^{85}$ in the pulmonary artery (counts/cuvet/min); $\mathrm{C}_{\mathrm{a}}=$ concentration of $\mathrm{Kr}^{85}$ in the brachial artery (counts/ cuvet $/ \mathrm{min}) ; Q_{\mathrm{Kr}}=$ flow calculated from $\frac{\dot{\mathrm{q}}_{\mathrm{I}} \mathrm{C}_{\mathrm{I}}}{\mathrm{C}_{\mathrm{PA}}-\mathrm{C}_{\mathrm{z}}}(\mathrm{L} / \mathrm{min}) ; Q_{\text {Fick }}=$ flow calculated from Fick equation $(\mathrm{L} / \mathrm{min})$.

infusate along the catheter from the proximal to the distal terminal opening. Following placement of the catheters and cannulation of a brachial artery with a Cournand needle, the patient was allowed to rest, during which time blood pressures and ventilation were measured. Subsequently, in the eight studies involving exercise, the patient's feet were placed in the stirrups of a a horizontal bicycle ergometer. The degree of resistance and rate of pedalling were adjusted, after a preliminary trial the day before the study, so that the exercise was sufficient to double or triple the resting oxygen uptake.

After the patient had been made comfortable with his feet in the bicycle ergometer, he was connected to a Tissot spirometer. To reduce radiation hazard, it was necessary to collect all expired air throughout the infusion period and for 5 minutes thereafter.

The infusion of krypton was begun at a constant rate through the right atrial catheter. During the next 9 minutes ventilation was continuously measured and when it became stable, the cardiac output was determined by the direct Fick method. In addition, from the fourth through the ninth minute, samples of blood were drawn in 5 seconds at 1 minute intervals from the pulmonary and brachial arteries for estimation of right ventricular output by the krypton method. It was found that for sampling at such frequent intervals a no. 8 or 9 single lumen Cournand catheter was most satisfactory. Smaller catheters frequently clotted or the resistance encountered in sampling led to air leaks or to foaming of the samples with concomitant extraction of krypton from the blood phase.

Following the direct Fick estimate of cardiac output at rest, usually after the ninth minute of infusion, the patient was instructed to begin exercise abruptly and to maintain the same rate of pedalling throughout the test. Sampling of blood at 1 minute intervals continued. In some instances samples were taken more frequently during the first minute. After exercise had been maintained for at least 5 minutes, a second measurement of cardiac output by the direct Fick method was made.

\section{RESULTS}

The data recorded in a typical study are presented in Table I. Also recorded are the values

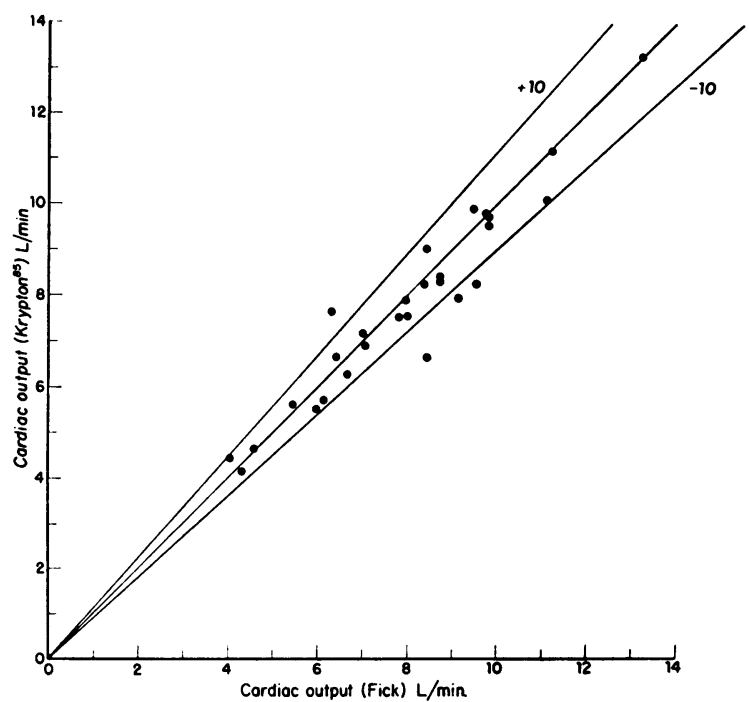

Fig. 3. Graph showing 28 comparisons of cardiac OUTPUT IN 15 PATIENTS BOTH AT REST AND DURING A STEADY STATE OF EXERCISE, AS DETERMINED BY THE $\mathrm{KR}^{8 \mathrm{8}}$ AND THE DIRECT FICK METHODS. The line of perfect agreement and the lines of \pm 10 per cent deviation are shown. 
CARDIAC OUTPUT AT REST AND EXERCISE MEASURED BY KRYPTON ${ }^{85}$

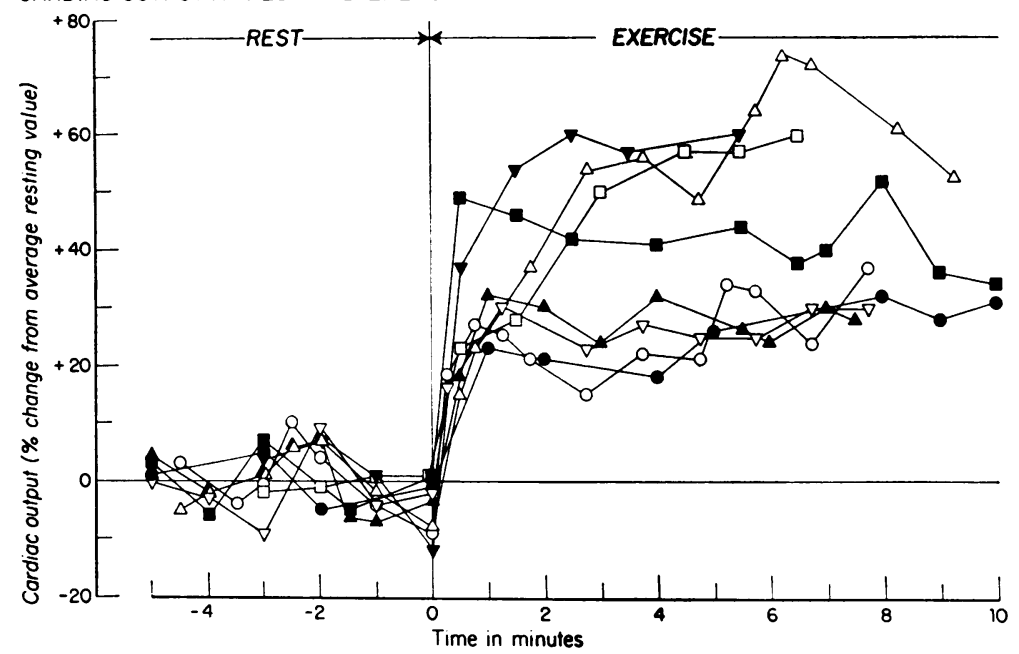

Fig. 4. Graphic Representation of Cardiac outPut as Determined by THE KRYPTON METHOD AT REST AND DURING EXERCISE IN EIGHT SUBJECTS. For each subject the output value at each point during rest and exercise is expressed as the percentage difference from the average value of the cardiac output of that patient at rest.

of cardiac output calculated by the $\mathrm{Kr}^{85}$ and conventional Fick methods.

A comparison of the $\mathrm{Kr}^{85}$ and Fick outputs obtained in all of the subjects is shown in Figure 3. The data are based on 28 simultaneous determinations made in 15 patients. Twenty of the measurements were made at rest and eight during steady state exercise. In each instance the $\mathrm{Kr}^{85}$ output was calculated by averaging the values of $\left(C_{\mathbf{P A}}-C_{\mathbf{B A}}\right)$ determined within 1 minute of the Fick measurement. Significantly, as seen in Figure 3 , the values by the $\mathrm{Kr}^{85}$ method were within \pm 10 per cent in all but four cases. In these latter instances, the blood flow by the $\mathrm{Kr}^{85}$ method differed from the Fick by $-13,-14,-21$ and +20 per cent, respectively.

The response of blood flow during the early phase of exercise as determined by the $\mathrm{Kr}^{85}$ method is depicted in Figure 4. In all eight patients the cardiac output rose immediately; in five it reached a plateau within 0.5 minute, and in the sixth within 1 minute; in the two remaining patients, the plateau was reached somewhat later.

\section{DISCUSSION}

The main advantages of the method are the ability to estimate the right ventricular output not only in steady but also in transient states, and the possibility of repeating those measurements at frequent intervals. As many as five determinations can be made in 1 minute which will reflect almost immediately the changes occurring in blood flow. Since $\mathrm{Kr}^{85}$ is poorly soluble, recirculation presents only a minor problem. Because of the very short biological half-life of this gas, radiation exposure to the patient, with the doses used, is minimal.

The disadvantages of this method are primarily technical. Utmost care must be taken in the handling of samples containing krypton to avoid its escape from the liquid into the gas phase. Measurements cannot be made for longer than 30 minutes because patients are not comfortable if they remain attached to the equipment for collection of expired air for longer than this time. The amount of blood loss may be considerable, since for each determination at least $10 \mathrm{ml}$ must be withdrawn for measurement with the type of equipment in current use.

In patients with emphysema, the recirculation problem is more important because less krypton is cleared from the circulation by the lungs. In such patients the error of estimation of cardiac output induced by substituting $C_{a}$ for $C_{\bar{v}}$ may be as much as 10 per cent in extreme cases.

The principles and primary assumptions of the 
krypton technique have been validated by the close agreement between the values for cardiac output secured by this method and the direct Fick, both at rest and during a steady level of exercise. Thus the errors inherent in both methods must be small.

While there is good agreement between the values for output obtained by the Fick and $\mathrm{Kr}^{85}$ methods, there are, nonetheless, fluctuations in the levels of blood flow as determined from minute to minute at rest by the krypton technique (Figure 4). The maximum variations in any one case were \pm 10 per cent of the average value. These variations may reflect technical errors, but may equally well mirror true variations in blood flow.

During the transient phase of exercise in man it is impossible to compare values of blood flow obtained by the krypton technique with those of another method. Therefore, the only arguments that can be invoked in favor of the accuracy of the data are based on indirect evidence: 1 ) the rise in cardiac output during exercise was abrupt in all eight patients and reached a plateau before the end of the first half minute in five, and 2) the values for blood flow obtained simultaneously by the krypton method and the direct Fick were in close agreement when exercise was prolonged sufficiently to validate the latter method.

\section{SUMMARY}

A technique is described for the measurement of pulmonary blood flow in man using a constant infusion of $\mathrm{Kr}^{85}$.

The theoretical and practical advantages and limitations are discussed and the applicability of the method in steady and changing conditions of cardiac output demonstrated.

Blood flow measured by this method and by the direct Fick, both at rest and in a steady state of exercise, agreed within 10 per cent in 24 of 28 determinations.

Measurements of blood flow made during the early minutes of exercise showed that there was a rise in output within the first minute of exercise, which in six of eight patients was maintained throughout the exercise period.

\section{ACKNOWLEDGMENT}

The authors wish to thank Dr. Andre Cournand for his helpful advice and encouragement.

\section{REFERENCES}

1. Fishman, A. P., McClement, J., Himmelstein, A., and Cournand, A. Effects of acute anoxia on the circulation and respiration in patients with chronic pulmonary disease studied during the "steady state." J. clin. Invest. 1952, 31, 770.

2. Fritts, H. W., Jr., and Cournand, A. The application of the Fick principle to the measurement of pulmonary blood flow. Proc. nat. Acad. Sci. (Wash.) 1958, 44, 1079.

3. Shepherd, J. T., Bowers, D., and Wood, E. H. Measurement of cardiac output in man by injection of dye at a constant rate into the right ventricle or pulmonary artery. J. appl. Physiol. 1955, 7, 629.

4. Chidsey, C. A., III, Fritts, H. W., Jr., Hardewig, A., Richards, D. W., and Cournand, A. The fate of radioactive krypton $\left(\mathrm{Kr}^{85}\right)$ introduced intravenously in man. J. appl. Physiol. 1959, 14, 63.

5. Fritts, H. W., Jr., Hardewig, A., Rochester, D. F., Durand, J., and Cournand, A. Estimation of pulmonary arteriovenous shunt-flow using intravenous injections of $\mathrm{T}-1824$ dye and $\mathrm{Kr}^{85}$. J. clin. Invest. 1960, 39, 1841.

6. Lassen, N. A., and Munck, O. The cerebral blood flow in man determined by use of radioactive krypton. Acta physiol. scand. 1955, 33, 30.

7. Hardewig, A., Rochester, D. F., and Briscoe, W. A. Measurement of solubility coefficients of krypton in water, plasma and human blood, using radioactive $\mathrm{Kr}^{85}$. J. appl. Physiol. 1960, 15, 723. 